\title{
THE CHOICE OF APPORTIONMENT FACTORS UNDER FORMULA APPORTIONMENT
}

\author{
MARCO RUNKEL \\ GUTTORM SCHJELDERUP
}

\section{CESIFO WORKING PAPER NO. 2072 \\ CATEgory 1: Public FinANCE \\ August 2007}

Presented at CESifo Area Conference on Public SeCtor Economics, April 2007

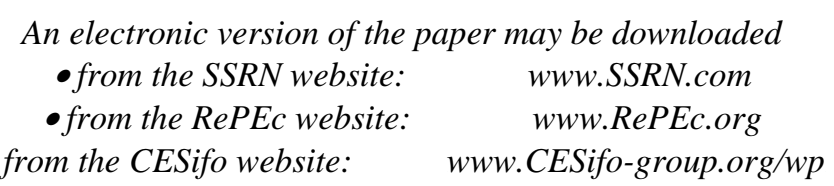




\title{
THE CHOICE OF APPORTIONMENT FACTORS UNDER FORMULA APPORTIONMENT
}

\begin{abstract}
This paper investigates the choice of apportionment factors under a corporate tax system of Formula Apportionment. In contrast to perceived wisdom, we show that the apportionment formula contains both mobile (capital) and immobile (labor) factors if jurisdictions are granted full fiscal autonomy with respect to tax rates and the formula design. A welfare gain can be realized by delegating the decision over apportionment factors to a central planner (centralization), while at the same time allowing jurisdictions fiscal autonomy in setting tax rates. However, the central planner uses the formula as a corrective instrument to internalize fiscal externalities and, therefore, uses mobile apportionment factors as well.
\end{abstract}

JEL Code: H25, H71, H87.

Keywords: corporate income taxation, Formula Apportionment, apportionment factors.

\author{
Marco Runkel \\ Department of Economics \\ University of Munich \\ Ludwigstr. 28/Vgb./III \\ 80539 Munich \\ Germany \\ marco.runkel@Irz.uni-muenchen.de
}

\author{
Guttorm Schjelderup \\ Department of Finance and Management \\ Science \\ Norwegian School of Economics and \\ Business Administration \\ Helleveien 30 \\ 5045 Bergen \\ Norway \\ guttorm.schjelderup@nhh.no
}

\section{$14^{\text {th }}$ May 2007}

We would like to thank Andreas Haufler, Eckard Janeba, Jukka Pirttilä, Marco Sahm, Jay Wilson and participants of the CESifo Area Conference on Public Sector Economics and seminars at the University of Munich, the University of Helsinki and the ZEW in Mannheim for helpful comments. Both authors gratefully acknowledge financial support from the Ruhrgas Foundation and the Research Council of Norway. The usual disclaimer applies. 


\section{Introduction}

Many federal countries like the U.S., Canada, Germany and Switzerland tax corporate income by Formula Apportionment, and the European Commission (Commission 2001a,b) has recommended that Formula Apportionment is implemented within the European Union. Under such a taxation system a multinational enterprise consolidates the income of its affiliates into a single measure of federal/global taxable income, which is then allocated (apportioned) among jurisdictions according to a certain formula reflecting the corporate group's activity within each jurisdiction. In most countries using Formula Apportionment taxation, the formula equals some combination of

the multinational's property, payroll and sales shares in the taxing jurisdictions. A hotly debated question in almost all existing and planned Formula Apportionment tax systems is which weights the three apportionment factors should receive in the formula (see e.g., Martens-Weiner 2005).

It is well known that a Formula Apportionment system transforms the corporate income tax into a tax on the apportionment factors (McLure, 1980). It has therefore been suggested by McLure (1980) and Wellisch (2004) among others, to leave internationally mobile capital out of the formula, since a tax on capital would be fully passed on to internationally immobile factors such as immobile labor and land. The lenient taxation of mobile capital is also a policy advice that follows from the standard workhorse model of tax competition (see e.g., Gordon 1986). The interesting point in this paper is that we can show, in contrast to previous studies, that this insight does not apply to corporate taxation under Formula Apportionment and that it is always optimal to include both mobile and immobile factors in the apportionment formula.

We first prove this result in a decentralized setting, where jurisdictions are granted full fiscal autonomy in the sense that they can choose both the corporate tax rates and the formula weights placed on mobile (capital) and immobile (labor) apportionment factors. In such a scenario the positive formula weight on capital follows from the application of the general principle that a tax on capital is an efficient way of taxing economic rents (e.g. Keen and Piekkola, 1997): The Formula Apportionment principle is usually applied in the taxation of corporate income so that it is plausible to assume the existence of economic rents that can be taxed. In our framework, rents are caused by decreasing returns to scale in production. Hence, by placing a positive weight on 
capital in the apportionment formula, each jurisdiction partially turns the corporate income tax into a tax on capital thereby shifting a part of the multinationals' rents to domestic workers whose wage income and welfare increase, compared to a formula with labor as the sole apportionment factor.

Due to the positive formula weight on capital, the corporate tax rate distorts the capital allocation thereby causing a fiscal externality (formula externality). Furthermore, Formula Apportionment creates fiscal externalities related to the private income and the consolidated tax base. These externalities explain why the formula weight on capital is still positive in a centralized setting, where jurisdictions set tax rates whereas formula weights are chosen by a central planner: Compared to the decentralized decision structure, the central planner increases welfare by using the formula as a corrective instrument to internalize the fiscal externalities alluded to above. Setting the weight on capital equal to zero eliminates the formula externality, but not the private income and tax base externalities. We can show that it is always possible to reduce the sum of externalities in absolute terms by increasing the weight on capital to a positive value, and it may even be optimal for the central planner to put a larger weight on capital than in a fully decentralized world. The interesting point here is that this result is independent of the general principle of capital taxation as a means of taxing economic rents. Put differently, the centrally chosen weight on capital may be positive even in the absence of rents (constant returns to scale), since the central planner then still wants to internalize fiscal externalities caused by Formula Apportionment.

There is some evidence in support of our findings from the U.S. Formula Apportionment system, where corporate tax rates and the apportionment factors are chosen decentrally by the states. Martens-Weiner (2005a) documents that none of the 46 states with a corporate income tax uses only immobile factors in their apportionment formula. As a matter of fact, all but three states use mobile capital as apportionment factor. The average weight placed on the capital factor is almost equal to that placed on labor, and amounts to roughly 25\%. Our result that under full fiscal autonomy with regard to tax rates and formula weights jurisdictions use both mobile and immobile apportionment factors, is in accordance with these observations.

The results of our analysis also have important policy implications. For example, in a potential European Formula Apportionment system the European Commission rather 
than the member countries should decide on the apportionment formula, and this formula should contain a capital factor. Another example is the German local business tax on multiregional companies that uses a formula that is centrally chosen and contains labor as the sole apportionment factor. Centralization is supported by our analysis, but the results imply that efficiency gains in the German system can be realized if capital is included in the formula. Finally, in the U.S. Formula Apportionment system Article IV of the Multistate Tax Compact from 1967 initially committed all states to use the so-called Massachusetts formula that contains a capital factor (with a weight of one third). Such a setting resembles the centralized formula choice in our analysis. However, after the famous Moorman vs. Bair decision of the U.S. Supreme Court in 1978, many states deviated from the Massachusetts formula and the choice of the apportionment factors is by now in fact decentralized. Our results suggest that this development is detrimental to welfare and that the states can realize welfare gains by returning to a compact that commits the states to use a common apportionment formula, provided this formula contains a capital factor.

Our paper is part of a very small literature that considers the choice of apportionment factors under Formula Apportionment. ${ }^{2}$ Wellisch (2004) shows that under full autonomy jurisdictions use only immobile factors in their formula and that the corporate tax rates do not create fiscal externalities which need corrective measures by a central authority. The reason for the difference to our results is that Wellisch (2004) assumes constant returns to scale and a consolidated tax base equal to the fixed sum of capital invested in the firm's affiliates. However, in the context of corporate income taxation it seems to be more plausible to assume decreasing returns to scale (since this generate economic rents that can be taxed) and a consolidated tax base equal to taxable profits, as in our framework.

Anand and Sansing (2000) consider the choice of apportionment factors in a setting where states differ in their demand for consumption goods. They show theoretically and empirically, that in a decentralized setting importing states have an incentive

\footnotetext{
${ }^{2}$ There is a rapidly growing literature on corporate taxation under Formula Apportionment versus Separate Accounting. See Gordon and Wilson (1986), Eggert and Schjelderup (2003), Nielsen et al. (2003, 2004), Sørensen (2004), Kind et al. (2005), Gérard (2005, 2006), Pethig and Wagener (2006) and Riedel and Runkel (2006). But none of these studies discusses the choice of apportionment factors.
} 
to place more weight on the sales factor than exporting states. As a consequence the efficient solution, which implies an equal formula across states, is not achieved in equilibrium. Their results hinge on a beggar-thy-neighbour type of policy, where states have unilateral incentives to deviate from a coordinated solution leading to a typical Prisoner's Dilemma situation. Related to their study, we show that the decentralized choice of apportionment factors may render corporate income taxation inefficient even in the absence of country asymmetries. Different from their study, however, is the fact that our model contains two factors as opposed to one immobile in their setting. Anand and Sansing (2000), therefore, cannot answer the question of how to distribute the tax burden between mobile and immobile factors. They also assume a fixed tax rate, and therefore do not work out the implications of the formula design for the efficiency properties of corporate income tax rates.

The paper is organized as follows. The next section describes the behavior of a representative multinational. In Section 3, we investigate the cooperative (Pareto efficient) tax policy as a benchmark. Sections 4 and 5 then analyze the decentralized and centralized choice of apportionment factors, respectively. Section 6 concludes.

\section{Multinational Firms}

We consider two countries, $a$ and $b$, which are identical in all respects. There is a representative multinational firm that operates a subsidiary in both countries. The firm employs $k_{i}$ units of capital and $\ell_{i}$ units of labor in order to produce $F\left(k_{i}, \ell_{i}\right)$ units of an output good whose price is normalized to one. The production function $F$ exhibits positive and decreasing returns to each input, i.e. $F_{x}>0$ and $F_{x x}<0$ for $x \in\left\{k_{i}, \ell_{i}\right\}$. Capital and labor are complements $\left(F_{k \ell}>0\right)$, and $F$ is homogenous of

degree $\eta \in] 0,1\left[\right.$ so that $F\left(\theta k_{i}, \theta \ell_{i}\right)=\theta^{\eta} F\left(k_{i}, \ell_{i}\right)$ for all $\theta>0$. The condition $\left.\eta \in\right] 0,1[$ implies that the production function shows decreasing returns to scale. This property implicitly assumes a fixed third production factor like, e.g., entrepreneurial services, which gives rise to economic rents. The case of constant returns to scale is obtained in the limiting case of $\eta \rightarrow 1$, where economic rents converge to zero.

Capital is assumed to be perfectly mobile and is supplied to the multinational in the international capital market at a per unit cost equal to $r>0$. Countries $a$ and $b$ are 
small compared to the rest of the world so $r$ is exogenously given. Labor is immobile internationally. There is a local labor market in each country, and the multinational demands labor in country $i$ at the wage rate $w_{i}>0$. Assuming a fixed labor supply $\bar{\ell}$ the wage rate in country $i$ is determined by the labor market equilibrium condition

$$
\ell_{i}=\bar{\ell}
$$

The demand for labor depends on the wage rates according to the multinational's profit maximization conditions which we derive below.

The pre-tax profit of the subsidiary located in country $i$ is

$$
\pi_{i}=F\left(k_{i}, \ell_{i}\right)-r k_{i}-w_{i} \ell_{i}
$$

Taxable profit differs from pre-tax profit if the cost of capital and/or depreciation are not fully deductible. It is well known that this type of distortion is the most common distortion in the taxation of corporations, and in order to investigate how it affects the analytical results we denote $\rho \in[0,1]$ as the share of interest expenses that is tax deductible. Taxable profit income (the tax base) of the subsidiary in country $i$ is

$$
\pi_{i t}=F\left(k_{i}, \ell_{i}\right)-\rho r k_{i}-w_{i} \ell_{i}
$$

Since the issue at hand here is the choice of apportionment factors, we shall assume that $\rho$ is fixed and equal across countries. ${ }^{3}$

The multinational is taxed according to the Formula Apportionment principle. Under Formula Apportionment, taxable profit in the two countries is consolidated and then apportioned according to a certain formula. The consolidated tax base equals

\footnotetext{
${ }^{3}$ These assumptions can be motivated by empirical observations. For example, in the Formula Apportionment system of Canada all provinces use the federal tax base definition for corporations. Furthermore, the Formula Apportionment system proposed by the European Union intends to use a common tax base definition. Finally, in calculating taxable income of corporations, every U.S. state starts with the federal tax base definition, even though some state-specific tax rules lead to slight differences in the tax base definition across states. These examples suggest that differences in the tax base definition are less relevant in Formula Apportionment tax systems. The assumption of a fixed $\rho$ may be supported by the observation that at least in the U.S. system there have been substantial variations in the apportionment formulas over the last decades while changes in the tax base definition were moderate. For a detailed discussion see Martens-Weiner (2005b).
} 
$\pi_{a t}+\pi_{b t}{ }^{4}$ The multinational's relative capital and labor shares serve as apportionment factors. The weight that the government of country $i$ places on capital and labor is $\gamma_{i} \in[0,1]$ and $\left(1-\gamma_{i}\right) \in[0,1]$, respectively. We let $\tau_{i} \in[0,1]$ be the corporate tax rate of country $i$, which allows us to express the effective tax rate in country $i$ as

$$
\tilde{\tau}_{i}=\tau_{i}\left[\gamma_{i} \frac{k_{i}}{k_{a}+k_{b}}+\left(1-\gamma_{i}\right) \frac{\ell_{i}}{\ell_{a}+\ell_{b}}\right] .
$$

The expression in the squared bracket equals the share of the consolidated tax base that is allocated to country $i$. In some Formula Apportionment systems, a third factor such as sales is employed. Since the purpose here is to investigate whether the tax falls on mobile or immobile factors, it suffices to have one immobile factor (labor) and one mobile factor (capital). The sales factor can therefore be ignored at the benefit of less complexity. It should be emphasized, however, that all our basic insights would hold if we were to introduce sales as a third apportionment factor.

Using equations (2)-(4) the after-tax profit of the multinational can be written as

$$
\pi=\pi_{a}+\pi_{b}-\bar{\tau}\left(\pi_{a t}+\pi_{b t}\right)
$$

where

$$
\bar{\tau}=\tilde{\tau}_{a}+\tilde{\tau}_{b}
$$

is the effective tax rate on the consolidated tax base of the multinational. Taking equation (4) into account, we see that the effective tax rate equals the weighted average of the national tax rates $\tau_{a}$ and $\tau_{b}$, where the weights are equal to the shares of the consolidated tax base of the multinational allocated to the two countries.

The multinational maximizes the after-tax profit (5) with respect to capital $k_{i}$ and labor demand $\ell_{i}$ for $i \in\{a, b\}$. In doing so, it takes as given the factor prices and the policy instruments. The first-order conditions are given by the following expressions

$$
\begin{aligned}
\frac{\partial \pi}{\partial k_{i}} & =(1-\bar{\tau}) F_{k}\left(k_{i}, \ell_{i}\right)-(1-\rho \bar{\tau}) r-\frac{\partial \bar{\tau}}{\partial k_{i}}\left(\pi_{a t}+\pi_{b t}\right)=0, \\
\frac{\partial \pi}{\partial \ell_{i}} & =(1-\bar{\tau})\left[F_{\ell}\left(k_{i}, \ell_{i}\right)-w_{i}\right]-\frac{\partial \bar{\tau}}{\partial \ell_{i}}\left(\pi_{a t}+\pi_{b t}\right)=0
\end{aligned}
$$

\footnotetext{
${ }^{4}$ We ignore the issue of profit shifting to low tax jurisdictions, since it is well known that the firm cannot reduce its tax payments by transfer pricing due to consolidation of tax bases (see e.g., Nielsen et al. 2004).
} 
with

$$
\frac{\partial \bar{\tau}}{\partial k_{i}}=\frac{k_{j}\left(\tau_{i} \gamma_{i}-\tau_{j} \gamma_{j}\right)}{\left(k_{a}+k_{b}\right)^{2}}, \quad \frac{\partial \bar{\tau}}{\partial \ell_{i}}=\frac{\ell_{j}\left[\tau_{i}\left(1-\gamma_{i}\right)-\tau_{j}\left(1-\gamma_{j}\right)\right]}{\left(\ell_{a}+\ell_{b}\right)^{2}}
$$

for $i, j \in\{a, b\}$ and $i \neq j$. If we ignore the terms containing the derivatives of the effective tax rate $\bar{\tau}$, the first-order conditions (7) and (8) equate the marginal return of the input factors to the factor cost. Since capital cost may be deductible, the marginal return of capital is computed after taxation, whereas for labor the before-tax marginal return is relevant. The terms containing the derivatives of $\bar{\tau}$ in (7) and (8) reflect the incentive that the multinational has to manipulate the apportionment formula in order to save tax payments (see e.g., Gordon and Wilson 1986). If the 'effective' tax burden on capital in country $i$ is larger than that in country $j$, i.e. $\tau_{i} \gamma_{i}>\tau_{j} \gamma_{j}$, then from (9) it follows that $\partial \bar{\tau} / \partial k_{i}>0>\partial \bar{\tau} / \partial k_{j}$. Thus, from (7) we see that the multinational tends to invest more in country $j$ than in country $i$, since by doing so it increases its activity in the low tax country thereby reducing the effective tax rate $\bar{\tau}$. An analogous interpretation holds with respect to labor demand.

Equations (7) and (8) determine inter alia the multinational's demand for labor as a function of the wage rates. Inserting these labor demand functions into the labor market equilibrium condition (1), yields the equilibrium wage rates in the two countries. Formally, we may insert (1) into (7) and (8) and obtain a system of four equations in four unknowns $\left(k_{i}\right.$ and $w_{i}$ for $\left.i \in\{a, b\}\right)$. In order to set the stage for the analysis to follow, we conduct a comparative static analysis of the optimal investment choice and the equilibrium wage rates. To keep the focus on the strategic incentives that face the governments, we shall restrict our attention to a symmetric situation where both countries have the same tax rate and the same formula weight, i.e. $\tau_{a}=\tau_{b}=\tau$ and $\gamma_{a}=\gamma_{b}=\gamma$. Equations (1)-(9) then imply $k_{a}=k_{b}=k, \ell_{a}=\ell_{b}=\bar{\ell}, w_{a}=w_{b}=w$, $\pi_{a t}=\pi_{b t}=\pi_{t}$, and $\bar{\tau}=\tau$. Comparative static results are then found by differentiating (7) and (8) and applying symmetry afterwards. With respect to the impact of country $i$ 's tax rate on the multinational's optimal investment levels, we obtain ${ }^{5}$

$$
\begin{aligned}
& \frac{\partial k_{i}}{\partial \tau_{i}}=\frac{1}{(1-\tau) F_{k k}}\left(\sigma+\frac{\gamma \pi_{t}}{2 k}\right), \\
& \frac{\partial k_{j}}{\partial \tau_{i}}=\frac{1}{(1-\tau) F_{k k}}\left(\sigma-\frac{\gamma \pi_{t}}{2 k}\right)
\end{aligned}
$$

\footnotetext{
${ }^{5}$ All comparative static results are proven in the Appendix.
} 
for $i, j \in\{a, b\}$ and $i \neq j$, with

$$
\sigma=\frac{(1-\rho) r}{2(1-\tau)}
$$

From (10) and (11) we see that if the cost of capital is fully deductible $(\rho=1, \sigma=0)$ and capital does not enter the apportionment formula $(\gamma=0)$, a rise in $\tau_{i}$ does not affect capital investment. In this case the corporate tax is a tax on pure profit. In general, however, the normal distortions are to be expected. If true profit differs from taxable profit $(\rho \in[0,1[, \sigma>0)$, or if capital enters the apportionment formula $(\gamma>0)$, the multinational's response when it comes to its investments following an increase in $\tau_{i}$, can be decomposed into two effects: a tax base effect and a formula effect.

The tax base effect is given by $\sigma$ in (10) and (11) and pertains to the definition of the tax base. If $\rho \in[0,1[$ and thus $\sigma>0$, tax deductions are incomplete and a rise in the tax on capital $\left(\tau_{i}\right)$ means that the effective tax rate rises. In response to this and in order to save tax payments, the multinational lowers its investment in both countries. The formula effect is reflected by the terms containing $\gamma$ in (10) and (11), and relates to the incentive the multinational has to manipulate the formula in order to reduce its tax burden. If the weight on capital in the formula is non-zero $(\gamma>0)$, a rise in $\tau_{i}$ makes it more costly to invest in country $i$. Thus, the multinational firm reallocates capital from country $i$ to country $j$, thereby reducing the part of consolidated profit taxed in country $i$ and the effective tax rate it faces. Taking both the tax base and the formula effect together, it is seen from equation (10) that investment in country $i$ is affected negatively. The sign of the total effect on investment in country $j$, however, is indeterminate as seen from equation (11).

The impact of a change in country $i$ 's tax rate on the equilibrium wage rates is

$$
\begin{aligned}
\frac{\partial w_{i}}{\partial \tau_{i}} & =-\frac{1}{(1-\tau) F_{k k}}\left[F_{k k} \frac{(1-\gamma) \pi_{t}}{2 \bar{\ell}}-F_{k \ell}\left(\sigma+\frac{\gamma \pi_{t}}{2 k}\right)\right], \\
\frac{\partial w_{j}}{\partial \tau_{i}} & =\frac{1}{(1-\tau) F_{k k}}\left[F_{k k} \frac{(1-\gamma) \pi_{t}}{2 \bar{\ell}}+F_{k \ell}\left(\sigma-\frac{\gamma \pi_{t}}{2 k}\right)\right] .
\end{aligned}
$$

In contrast to the conditions for investment choice there is no (direct) tax base effect in equations (13) and (14), since labor cost is fully deductible. There is still a formula effect if the weight on labor is positive $(\gamma<1)$. The reason is that an increase in $\tau_{i}$ induces the multinational to demand less labor in country $i$ and more labor in country $j$ in order to reduce the part of taxable income assigned to the tax increasing country 
$i$. Consequently, the wage rate in country $i$ falls and the wage rate in country $j$ rises. This effect is given by the first term in the squared brackets of equations (13) and (14). There is a secondary effect on labor demand and wages from a rise in $\tau_{i}$, since labor is connected to capital by the positive cross derivative of the production function. Complementarity means that a decrease (increase) in investment reduces (raises) labor demand and the wage rate. These effects are given by the second term in the squared brackets of equations (13) and (14). If the cost of capital is not fully deductible ( $\rho \in$ $[0,1[, \sigma>0)$, and the apportionment formula uses both factors $(0<\gamma<1)$, it is seen from equations (13) and (14) that in total a rise in $\tau_{i}$ causes $w_{i}$ to fall, while the effect on country $j$ 's wage rate is ambiguous.

The comparative static effects of a change in country $i$ 's formula weight on the multinational's optimal investment decision are given by

$$
\frac{\partial k_{i}}{\partial \gamma_{i}}=-\frac{\partial k_{j}}{\partial \gamma_{i}}=\frac{\tau \pi_{t}}{2 k(1-\tau) F_{k k}}
$$

for $i, j \in\{a, b\}$ and $i \neq j$. If country $i$ raises its formula weight on capital, equation (15) states that the multinational reallocates capital from country $i$ to country $j$ since the tax burden on capital in country $i$ becomes higher. The impact of country $i$ 's formula weight on the equilibrium wage rates can be expressed as

$$
\frac{\partial w_{i}}{\partial \gamma_{i}}=-\frac{\partial w_{j}}{\partial \gamma_{i}}=\frac{\tau \pi_{t}}{2(1-\tau) F_{k k}}\left(\frac{F_{k k}}{\bar{\ell}}+\frac{F_{k \ell}}{k}\right)=\frac{\tau \pi_{t}(\eta-1) \bar{\ell}^{\eta-2} F_{k}\left(k_{i} / \ell_{i}, 1\right)}{2 k(1-\tau) F_{k k}} .
$$

Equation (16) shows that an increase in country $i$ 's formula weight on capital increases the wage rate in country $i$ and reduces the wage rate in country $j$ under decreasing returns to scale, i.e. $\eta \in] 0,1\left[\right.$. When country $i$ raises $\gamma_{i}$, labor in country $i$ becomes cheaper relative to labor in country $j$. The implication is that the demand for labor rises, leading to a higher wage rate in country $i$. The reversed effect holds with respect to labor demand and the wage rate in country $j$. Hence, the multinational allocates a larger part of its rents to workers in country $i$ than to workers in country $j$. In contrast, under constant returns to scale $(\eta \rightarrow 1)$, a change in the formula weight has no impact on wage rates, since there are no economic rents that can be distributed among the workers in the two countries.

The impact of the policy parameters $\left(\tau_{i}\right.$ and $\left.\gamma_{i}\right)$ on aggregate investment and aggregate wage income can be found by using equations (10)-(16). The result is

$$
\frac{\partial k_{i}}{\partial \tau_{i}}+\frac{\partial k_{j}}{\partial \tau_{i}}=\frac{2 \sigma}{(1-\tau) F_{k k}}, \quad \frac{\partial w_{i}}{\partial \tau_{i}}+\frac{\partial w_{j}}{\partial \tau_{i}}=\frac{2 \sigma F_{k \ell}}{(1-\tau) F_{k k}}
$$




$$
\frac{\partial k_{i}}{\partial \gamma_{i}}+\frac{\partial k_{j}}{\partial \gamma_{i}}=\frac{\partial w_{i}}{\partial \gamma_{i}}+\frac{\partial w_{j}}{\partial \gamma_{i}}=0
$$

for $i, j \in\{a, b\}$ and $i \neq j$. Equations (17) and (18) reveal an important qualitative difference between a change in country $i$ 's tax rate and country $i$ 's formula weight. A change in $\tau_{i}$ affects aggregate investment and wage income (when $\rho<1$ and $\sigma>0$ ), while a change in $\gamma_{i}$ does not affect total investment or wage income. From equations (15) and (16), the change in $k_{i}$ and $w_{i}$ following a rise in $\gamma_{i}$ is matched by changes of equal size but opposite sign of $k_{j}$ and $w_{j}$. A change in $\gamma_{i}$, therefore, is purely redistributive (as shown by equation (18)). Similarly, the formula effect stemming from a change in $\tau_{i}$ is purely redistributive in that it redistributes production factors from one country to the other without changing the aggregate variables. But a change in $\tau_{i}$ additionally triggers a tax base effect. This effect makes the multinational reduce total investment and, by the cross derivative of the production function, it also changes labor demand and the sum of wage income (as shown by equation (17)).

\section{Cooperative (Efficient) Policy}

In this section we study how taxes and apportionment weights should be set if the tax system is decided by a central authority in order to maximize the joint welfare of the two countries. This setting serves as a normative benchmark for the (partially) decentralized decision structures considered in the next sections.

To determine the cooperative solution, we have to specify welfare in the two countries. There is a representative household in country $i$ with a quasi-concave utility function $U\left(c_{i}, g_{i}\right)$, where $c_{i}$ is the consumption of a private good and $g_{i}$ is the consumption of a local public good. The household is endowed with $\bar{k}$ units of capital and $\bar{\ell}$ units of labor, both supplied inelastically at the world interest rate $r$ and the local wage rate $w_{i}$, respectively. Each household owns a share of the multinational denoted by $z_{i} \in[0,1]$ for $i \in\{a, b\}$ with $z_{a}+z_{b}=1$. To ensure that the two countries are identical in all respects we set $z_{a}=z_{b}=1 / 2$ throughout the analysis. It will, however, often be convenient to work with the general notations $z_{a}$ and $z_{b}$ rather than $1 / 2$. The private budget constraint can be written as

$$
c_{i}=r \bar{k}+w_{i} \bar{\ell}+z_{i} \pi
$$


which makes it clear that country $i$ 's private consumption is determined by the return to capital and labor plus profit income.

Without loss of generality we shall normalize the cost of the public good to one so that the marginal rate of transformation between private and public consumption equals one. Since the sole source of tax revenue stems from the corporate income tax, the public budget constraint in country $i$ is given by

$$
g_{i}=\tilde{\tau}_{i}\left(\pi_{a t}+\pi_{b t}\right)
$$

Inserting the private and public budget constraints (19) and (20) into the utility function, welfare in country $i$ can be written as

$$
V^{i}\left(\tau_{i}, \gamma_{i}, \tau_{j}, \gamma_{j}\right)=U\left[r \bar{k}+w_{i} \bar{\ell}+z_{i} \pi, \tilde{\tau}_{i}\left(\pi_{a t}+\pi_{b t}\right)\right]
$$

for $i, j \in\{a, b\}$ and $i \neq j$. To ensure existence and uniqueness of the solution to welfare maximization, each country's welfare function is assumed to be quasi-concave.

The cooperative solution is determined by the central planner who chooses $\tau_{i}$ and $\gamma_{i}$ for $i \in\{a, b\}$ such that the countries' joint welfare

$$
W\left(\tau_{a}, \gamma_{a}, \tau_{b}, \gamma_{b}\right)=V^{a}\left(\tau_{a}, \gamma_{a}, \tau_{b}, \gamma_{b}\right)+V^{b}\left(\tau_{b}, \gamma_{b}, \tau_{a}, \gamma_{a}\right)
$$

is maximized. In doing so, the central planner takes into account the impact of the chosen policy on the multinational's behavior represented by the first-order conditions (7)-(9) or, equivalently, by the comparative static results (10)-(18). The solution to this welfare maximization problem is Pareto efficient in the sense that no Pareto improvement can be attained. The terms 'efficient' and 'cooperative' are therefore used interchangeably. The cooperative solution can also be interpreted as the outcome of a fully centralized economy, since all policy instruments are chosen at the central level.

As both countries are identical, it is natural to assume that the central planner seeks a symmetric solution with $\tau_{a}=\tau_{b}=\tau^{*}$ and $\gamma_{a}=\gamma_{b}=\gamma^{*}$ where the asterisk indicates the efficient policy. This symmetric solution is characterized by ${ }^{6}$

Proposition 1 When a central planner maximizes joint welfare, he chooses the tax rates such that $U_{g} / U_{c}=1$ if $\rho=1$, and $U_{g} / U_{c}>1$ if $\rho \in[0,1[$. The central planner is indifferent between all formula weights $\gamma_{i} \in[0,1]$ for $i \in\{a, b\}$.

\footnotetext{
${ }^{6}$ The proofs to all Propositions are relegated to the Appendix.
} 
Proposition 1 makes it clear that the optimal corporate tax rate does not depend on the choice of apportionment weights. Hence, the central planner is indifferent when it comes to the choice of weights. Capital may therefore be part of the formula or it may not. The reason why the choice of weights does not matter can be explained by Coasean economics. Different apportionment formulas can be interpreted as different allocative institutions. Since we abstract from institution-specific costs, every institution yields the same efficient allocation.

The difference in public goods provision in Proposition 1 can be explained as follows. Assume initially that the cost of capital is fully deductible $(\rho=1, \sigma=0)$, in which case the corporate tax does not distort the multinational's total investment and thus neither labor demand nor wage rates (see (17)). In this case the cooperative policy coincides with the first-best outcome characterized by the Samuelson rule. When the cost of capital cannot be fully deducted $(\rho \in[0,1[, \sigma>0)$, equation (17) shows that the corporate tax distorts the multinational's investment decision and, by the cross derivative of the production function, we see that labor demand and wage rates are distorted, too. This restricts the efficient solution to a second-best optimum. The social planner then chooses the tax rates such that a modified Samuelson rule applies, with the marginal rate of substitution being larger than the marginal rate of transformation. In this case the public good is undersupplied relative to the first best since it is more costly to collect tax revenue.

\section{Decentralized Choice of Formula Weights}

In this section we consider the outcome when jurisdictions non-cooperatively choose both the corporate tax rates and the formula weights. Such a decision structure prevails, for example, in the U.S. Formula Apportionment system. Under full decentralization, country $i$ 's government chooses $\tau_{i}$ and $\gamma_{i}$ in order to maximize welfare as given by equation (21). In doing so, it takes into account the multinational's profit maxi-

mizing behavior represented by the first order conditions (7)-(9) or, equivalently, by the comparative static results (10)-(18). Moreover, country $i$ takes as given the corporate tax rate and formula weight chosen by country $j$. Hence, the countries play a non-cooperative Nash tax competition game with two instruments (the tax rate and 
the weight in the apportionment formula).

We follow the previous literature on Formula Apportionment and focus on a symmetric equilibrium with $\tau_{a}=\tau_{b}=\tau^{d}$ and $\gamma_{a}=\gamma_{b}=\gamma^{d}$, where the superscript $d$ indicates the fully decentralized case. The marginal effects of country $i$ 's tax rate and formula weight on country $i$ 's welfare are obtained by differentiating equation (21) and employing (1), (7), (9), (12), the symmetry property, and $d \pi / d \gamma_{i}=0$. This yields

$$
\begin{array}{rr}
\frac{\partial V^{i}(\cdot)}{\partial \tau_{i}}=U_{c}\left[\bar{\ell} \frac{\partial w_{i}}{\partial \tau_{i}}+z_{i} \frac{d \pi}{d \tau_{i}}\right]+U_{g}\left[\pi_{t}+\tau^{d} \sigma\left(\frac{\partial k_{i}}{\partial \tau_{i}}+\frac{\partial k_{j}}{\partial \tau_{i}}\right)-\frac{\tau^{d} \bar{\ell}}{2}\left(\frac{\partial w_{i}}{\partial \tau_{i}}+\frac{\partial w_{j}}{\partial \tau_{i}}\right)\right. & \left.+\frac{\tau^{d} \gamma^{d} \pi_{t}}{2 k}\left(\frac{\partial k_{i}}{\partial \tau_{i}}-\frac{\partial k_{j}}{\partial \tau_{i}}\right)\right], \\
\frac{\partial V^{i}(\cdot)}{\partial \gamma_{i}}=U_{c} \bar{\ell} \frac{\partial w_{i}}{\partial \gamma_{i}}+U_{g} \frac{\tau^{d} \gamma^{d} \pi_{t}}{2 k}\left(\frac{\partial k_{i}}{\partial \gamma_{i}}-\frac{\partial k_{j}}{\partial \gamma_{i}}\right), &
\end{array}
$$

for $i, j \in\{a, b\}$ and $i \neq j$.

Using (23) and (24) we are able to characterize the policy chosen in the fully decentralized economy. It is straightforward to show that $\gamma_{i}=0$ is not an optimal policy for country $i$. To see this, we evaluate (24) at the point $\gamma_{a}=\gamma_{b}=\gamma^{d}=0$ and obtain

$$
\left.\frac{\partial V(\cdot)}{\partial \gamma_{i}}\right|_{\gamma^{d}=0}=U_{c} \bar{\ell} \frac{\partial w_{i}}{\partial \gamma_{i}}
$$

From equation (16) we know that $\partial w_{i} / \partial \gamma_{i}$ is positive. Equation (25) then shows that a situation where each country places the whole formula weight on the immobile factor labor $\left(\gamma^{d}=0\right)$ cannot be a Nash equilibrium. Both countries have an incentive to deviate from such a policy, since the marginal welfare gain from reducing the weight on labor and increasing the weight on capital is positive. Hence, we may state

Proposition 2 Under full fiscal autonomy where jurisdictions decide on the tax rate and the apportionment formula non-cooperatively, the symmetric Nash equilibrium is characterized by both jurisdictions setting a positive weight on capital (the mobile factor), that is, $\gamma_{a}=\gamma_{b}=\gamma^{d}>0$.

As shown in (24), a marginal increase in the weight $\gamma_{i}$ has two effects on welfare in jurisdiction $i$. The first effect relates to that an increase in $\gamma_{i}$ makes labor in jurisdiction $i$ cheaper relative to labor in jurisdiction $j$ causing the multinational to demand more labor with rising wages and welfare in jurisdiction $i$ as an end result. The second effect 
pertains that an increase in $\gamma_{i}$ increases the tax burden on investment in country $i$ and so induces the multinational to reallocate capital from jurisdiction $i$ to jurisdiction $j$ resulting in a fall in tax revenue and welfare in jurisdiction $i$. At the margin with $\gamma_{i}=0$, only the first (positive) welfare effect remains. The second (negative) welfare effect disappears since the reallocation of capital occurs only if capital is part of the apportionment formula. Thus, starting from a situation where the formula uses labor as sole apportionment factor, it is beneficial from a single jurisdiction's perspective to reduce the weight placed on labor and increase the weight placed on capital. In the optimum, jurisdiction $i$ chooses $\gamma_{i}$ such that the (first) positive welfare effect on wage income is just offset by the (second) negative effect on investment.

It is important to emphasize that each jurisdiction places some tax burden on the mobile factor (capital) despite the fact that an immobile factor (labor) can be fully taxed. This follows from the general principle that mobile capital is taxed whenever firms obtain positive economic rents (e.g. Keen and Piekkola, 1997). If we apply this principle to the decentralized choice of apportionment factors under Formula Apportionment it is clear that each jurisdiction places a positive weight on capital since by doing so it turns the corporate income tax in parts into a tax on capital and so absorbs economic rents from the multinational. A simple check that the general principle applies in our model is to consider constant returns to scale as a limiting case: For $\eta \rightarrow 1$, the formula weight in country $i$ does not influence the wage rate (see equation (16)), and each country places the whole weight on immobile labor as implied by (15) and (24). The reason is that under constant returns to scale there are no economic rents accruing to the multinational. However, if we view corporate taxation as a tax on corporate income it seems more plausible to assume positive economic rents (caused, for example, by decreasing returns to scale). Positive rents imply that under Formula Apportionment a decentrally chosen formula always contains mobile factors.

We now turn to discuss whether taxes are set at an efficient level in the noncooperative Nash equilibrium. To answer this question, we have to investigate the fiscal externalities caused by the tax rates, that is, the effect of country $i$ 's tax rate on welfare in country $j$. If the fiscal externality is positive (negative) a coordinated tax rate increase (decrease) improves welfare in both countries and, thus, leads to a Pareto improvement. The equilibrium tax rate $\tau^{d}$ is then inefficiently low (high). Using the 
comparative static results in equations (10)-(14) and (17), the fiscal externalities in the tax competition equilibrium can be calculated from (21) as

$$
\frac{\partial V^{j}(\cdot)}{\partial \tau_{i}}=\mathrm{WE}+\mathrm{PE}+\mathrm{TE}+\mathrm{FE}
$$

with

$$
\begin{aligned}
\mathrm{WE} & =U_{c} \bar{\ell} \frac{\partial w_{j}}{\partial \tau_{i}}=U_{c} \frac{\bar{\ell} \pi_{t}}{2\left(1-\tau^{d}\right) F_{k k}}\left[\left(1-\gamma^{d}\right) \frac{F_{k k}}{\bar{\ell}}-\gamma^{d} \frac{F_{k \ell}}{k}\right]+U_{c} \frac{\sigma \bar{\ell} F_{k \ell}}{\left(1-\tau^{d}\right) F_{k k}} \\
\mathrm{PE} & =U_{c} z_{j} \frac{d \pi}{d \tau_{i}}=-U_{c} z_{j} \pi_{t}-U_{c} z_{j} \frac{2 \sigma \bar{\ell} F_{k \ell}}{F_{k k}} \\
\mathrm{TE} & =U_{g}\left[\tau^{d} \sigma\left(\frac{\partial k_{i}}{\partial \tau_{i}}+\frac{\partial k_{j}}{\partial \tau_{i}}\right)-\frac{\tau^{d} \bar{\ell}}{2}\left(\frac{\partial w_{i}}{\partial \tau_{i}}+\frac{\partial w_{j}}{\partial \tau_{i}}\right)\right]=U_{g} \frac{\tau^{d} \sigma\left(2 \sigma-\bar{\ell} F_{k \ell}\right)}{\left(1-\tau^{d}\right) F_{k k}} \\
\mathrm{FE} & =-U_{g} \frac{\tau^{d} \gamma^{d} \pi_{t}}{2 k}\left(\frac{\partial k_{i}}{\partial \tau_{i}}-\frac{\partial k_{j}}{\partial \tau_{i}}\right)=-U_{g} \frac{\tau^{d} \gamma^{d 2} \pi_{t}^{2}}{2 k^{2}\left(1-\tau^{d}\right) F_{k k}}
\end{aligned}
$$

As seen from the expressions above, the total cross country effect of the tax rate can be decomposed into four fiscal externalities. First, if country $i$ changes its tax rate, the multinational changes its labor demand so that the wage income in country $j$ is altered. This is the wage income externality WE determined by (27). Second, a change in the tax rate of country $i$ affects profit income in country $j$ as shown by the profit income externality PE given in (28). Third, as a reaction to the increase in country $i$ 's tax rate the multinational reduces total investment and labor demand. This causes a change in the consolidated tax base and tax revenue in both countries as indicated by the tax base externality TE in (29). Finally, a tax rate increase in country $i$ induces the multinational to reallocate capital from country $i$ to country $j$ thereby making tax revenue in country $j$ rise. This is the formula externality FE defined in (30).

The formula externality FE is the one which is caused by the countries' decision to place a positive formula weight on the capital apportionment factor $\left(\gamma^{d}>0\right)$. It distorts the corporate tax rate downwards since it is positive. However, equations (28)-(30) make it clear that even for a zero weight on capital there may be further externalities which are caused by the partial deductibility of capital cost $(\rho \in[0,1[$ and $\sigma>0)$, a foreign firm ownership of the multinational $\left(z_{j}=1 / 2>0\right)$, and/or a possibly positive weight on the labor apportionment factor $\left(1-\gamma^{d}>0\right)$. These insights allows us to make the following statement: 
Proposition 3 Under full fiscal autonomy, the symmetric Nash-equilibrium tax rates

(i) are set inefficiently low $\left(\tau^{d}<\tau^{*}\right)$ if $\rho=1$,

(ii) may be inefficiently low or high $\left(\tau^{d} \gtrless \tau^{*}\right)$ if $\rho \in[0,1[$.

Proposition 3 (i) shows that if capital cost is fully deductible $(\rho=1)$, tax competition leads to a race to the bottom with inefficiently low tax rates and underprovision of local public goods. It is the interplay of the fiscal externalities identified in (27)-(30) that causes this outcome. In particular, for $\rho=1$ we have $\sigma=0$, and the tax base effect identified in the comparative static analysis of the multinational's behavior vanishes. This implies that the tax base externality in $(29)$ becomes zero $(\mathrm{TE}=0)$. Moreover, wage and profit income is no longer influenced by changes in the tax base so that the wage income externality in (27) is positive ( $\mathrm{WE}>0$ ), and the profit income externality in $(28)$ is negative $(\mathrm{PE}<0)$. Though we obtain countervailing externalities, the sum of externalities, $\mathrm{WE}+\mathrm{PE}+\mathrm{FE}$, is positive. The reason is that the jurisdictions' choice of formula weights implies that the formula terms in the wage income externality WE (all terms containing $\gamma^{d}$ ) are just offset by the formula externality FE, and that the remaining term in the wage income externality WE (i.e., $U_{c} \pi_{t} / 2\left(1-\tau^{d}\right)$ ) is larger in absolute terms than the profit income externality $\mathrm{PE}=-U_{c} \pi_{t} / 2$.

This argument does not carry over to the case of partial deductibility of capital cost. When $\rho \in[0,1[$, we have $\sigma>0$ and the tax base effect reemerges. Hence, the tax base externality may be negative $(\mathrm{TE}<0)$, and the signs of the wage and profit income externalities, WE and PE, are ambiguous, since wage and profit income are now influenced by corporate tax rates also through the tax base effect. The sum of fiscal externalities, therefore, may be positive or negative implying an indeterminate relationship between the equilibrium tax rate and the efficient tax rate. As shown by Proposition 3 (ii) it may be the case that the jurisdictions then end up with inefficiently high tax rates and an overprovision of local public goods.

For the analysis to follow, we would like to point out that the positive formula weight on capital and the associated formula externality represent only one reason for the inefficiencies identified in Proposition 3. By allowing the corporate tax to fall on taxable corporate income, which is positive due to decreasing returns to scale and a possibly partial deductibility of capital cost, it turns out that there is an additional externality to the consolidated tax base as well as externalities on private income which 
are not present in previous studies. These externalities also distort the jurisdictions' tax policy and may even lead to inefficient overtaxation. This is the focal point of the next section.

\section{Centralized Choice of Formula Weights}

As an alternative to the economy with full autonomy we now turn to the case where the decisions on the apportionment formula are delegated to a central level. In Canada and Germany, for example, each state sets its tax rate, but the apportionment formula is decided on a federal level. Such a set up has also been suggested by the European Commission as the prime candidate for a European system of Formula Apportionment.

The decisions structure we examine is a two stage process. At the first stage, the central planner sets the (common) formula weight, taking into account the impact the choice of weight has on the tax rates chosen by the jurisdictions at the second stage. ${ }^{7}$ To ensure a subgame perfect equilibrium we start with the second stage. Here each country non-cooperatively sets its tax rate in order to maximize its residents' welfare, taking as given the tax rates chosen by the other country and the formula weight chosen by the central planner at the first stage. The first-order condition is again obtained by setting equation (23) equal to zero. Assuming a symmetric equilibrium of the tax competition game with $\tau_{a}=\tau_{b}=\tau$, and using the relation $W=V^{i}+V^{j}$, country $i$ 's first-order condition can be rewritten as

$$
\Psi(\tau)=\frac{\partial W(\cdot)}{\partial \tau_{i}}=\frac{\partial V^{j}(\cdot)}{\partial \tau_{i}}=\Phi(\tau, \gamma) .
$$

The function $\Psi$ is independent of the centrally chosen $\gamma$, since from Proposition 1 it follows that the joint welfare function $W$ and, thus, its derivatives is not influenced by

\footnotetext{
${ }^{7}$ An alternative to this two stage setting is to assume that jurisdictions and the central planner decide simultaneously. The jurisdictions then choose the tax rates in the same way as in the previous section, whereas the size of the externalities depends on the formula weight chosen by the central planner. But the central planner will again be indifferent between all formula weights because he has the same first-order condition as the central planner in the cooperative case considered in Section 3. Hence, no useful insight emerges from the analysis of a simultaneous decision structure. Moreover, the sequential decision structure seems to be more realistic since in Canada and Germany there have been virtually no changes in the formula, but tax rates change quite frequently implying that the central planner possesses larger commitment ability than jurisdictions.
} 
the formula weights. As the welfare function is assumed to be concave and the efficient solution is obtained by setting $\partial W(\cdot) / \partial \tau_{i}=0$, it is clear from equation (31) that the central planner sets the formula weight such that the absolute value of the fiscal externalities is minimized. Hence, the problem of the social planner can be written as

$$
\min _{\gamma}|\Phi(\tau, \gamma)|
$$

Denoting the solution to this minimization problem by $\gamma^{c}$, we obtain

Proposition 4 When the apportionment formula is set at a central level, but jurisdictions have fiscal autonomy over tax rates, welfare is higher than under full autonomy. The central planner sets $\left.\gamma^{c} \in\right] 0, \gamma^{d}\left[\right.$ if $\rho=1$. For $\rho \in\left[0,1\left[\right.\right.$, the formula weight $\gamma^{c}$ is positive and may be larger than $\gamma^{d}$.

Two messages follow from Proposition 4. First, jurisdictions can increase their welfare if they allow a central authority at the federal level, say, to decide on the structure of the apportionment formula. Second, even in a centralized setting it is optimal to use both capital and labor as apportionment weights, and it may be the case that the weight placed on capital is higher than under full autonomy. Hence, the conventional wisdom of not taxing mobile factors, since the tax burden will be fully shifted onto immobile factors, does not hold even under delegation of some authority when the tax system in place is Formula Apportionment. The main reason here is that the central planner uses the formula weight as a corrective instrument to minimize the distortions caused by the decentralized choice of tax rates.

In order to gain a deeper insight it is instructive to start by considering the case where capital cost is completely deductible $(\rho=1, \sigma=0)$ so that the tax base externality in $(29)$ vanishes $(\mathrm{TE}=0)$. In this case the central planner sets the formula weight below the value chosen under decentralization $\left(\gamma^{d}\right)$. Intuitively, a lower weight reduces the formula externality $\mathrm{FE}$ by more than the increase of the wage income externality WE (confer (27) and (30)). This is beneficial as the sum of externalities falls. However, it is never optimal for the central planner to reduce the formula weight on capital to zero. Indeed, at the margin, where $\gamma=0$, the formula externality FE vanishes, but the sum of the remaining wage and profit income externalities, WE and $\mathrm{PE}$, is still positive. A marginal increase in the formula weight to a small positive value, then, reduces the wage income externality WE, and leaves the formula externality $\mathrm{FE}$ as 
well as the profit income externality PE unchanged. As a result the sum of externalities again falls. The central planner, therefore, always chooses a positive weight on capital.

When $\rho \in[0,1[$ and $\sigma>0$, the same line of reasoning as above applies through with one important exception: the tax base externality TE reemerges. This externality may be negative possibly making the sum of fiscal externalities at $\gamma=0$ and $\gamma=\gamma^{d}$ negative. In such a case, the central planner can improve welfare by shifting the formula weight above the value chosen under decentralization. Intuitively, this increases the (positive) formula externality FE and so renders the sum of externalities less negative thereby implying a shift towards more efficient corporate tax rates. To sum up, with incomplete deductibility of capital cost the formula weight on mobile capital may even exceed the weight chosen in the decentralized equilibrium.

This latter insight is useful to highlight the novelty of Proposition 4. While the positive weight on capital under full autonomy (Proposition 2) is explained by the general principle of capital taxation as a means of taxing economic rents, the central planner's formula choice may yield a positive weight on capital even if this general principle does not apply, i.e. even if the multinational does not receive positive economic rents. To prove this assertion consider the limiting case of constant returns to scale $(\eta \rightarrow 1)$ where economic rents vanish. It is then straightforward to show and intuitively plausible that the income externalities WE and PE disappear. ${ }^{8}$ The sign of the tax base externality TE is indeterminate, in general. But if it is negative, ${ }^{9}$ the central planner chooses a positive formula weight on capital: At $\gamma^{c}=0$ the formula externality vanishes $(\mathrm{FE}=0)$ and the sum of externalities is negative $(\mathrm{FE}+\mathrm{TE}<0)$. Increasing $\gamma^{c}$ to a strictly positive value makes the formula externality positive $(\mathrm{FE}>0)$ and leaves the tax base externality unchanged. Hence, the sum of externalities falls in absolute terms thereby implying a welfare increase. This argument reveals that it is mainly the internalization of fiscal externalities that induces the central planner to place a positive weight on mobile capital in the apportionment formula.

\footnotetext{
${ }^{8}$ Formally, constant returns to scale imply $F_{k k} / \bar{\ell}+F_{k \ell} / k=0$. Inserting this together with $\pi_{t}=$ $2 k \tau \sigma=k \tau F_{k}(1-\rho) /(1-\rho \tau)$ into equations (27) and $(28)$ yields $\mathrm{WE}=\mathrm{PE}=0$.

${ }^{9}$ Consider, for example, a linear homogenous Cobb-Douglas production function $F(k, \ell)=k^{\alpha} \ell^{\beta}$ with $\alpha+\beta=1$. It is then straightforward to show that TE $<0$ if $\beta<(1-\rho) /\left(1-\rho \tau^{c}\right)$.
} 


\section{Conclusion and Discussion}

The globalization process and the rise in multinationality in the world economy have lead policymakers and academics to look for ways to make the corporate tax base less tax sensitive and vulnerable to profit shifting. In response to these challenges the European Commission has recommended a transition to Formula Apportionment taxation. Under Formula Apportionment it has been shown that the corporate income tax in essence becomes a tax on the factors used to apportion consolidated corporate income. Standard tax competition analysis would then suggest that a tax on perfectly internationally mobile capital is passed onto immobile factors such as labor. As a consequence, the apportionment weights should be on the factor that is not mobile internationally, since it has the lower tax sensitivity.

In this paper we have studied and compared the choice of apportionment weights under decentralization and centralization in a model with two countries and a multinational firm that has subsidiaries in both countries. In the decentralized economy, each jurisdiction sets its tax rate and formula weight non-cooperatively. In contrast to the above stated argument of the standard tax competition analysis, it is then optimal for each jurisdiction to use positive weights on both mobile (capital/investment) and immobile (labor/land) apportionment factors in order to appropriate some of the rents of the multinational firm. As a consequence of the jurisdictions' formula choice and of other fiscal externalities caused by the very nature of Formula Apportionment, corporate tax rates as well as the public goods supply may be inefficiently high or low.

Under a centralized decision structure, a social planner sets the apportionment weight while the jurisdictions at the same time choose the corporate tax rates. In such a setting we find that the central authority uses the apportionment weights as a corrective devise in order to reduce the distortions caused by the jurisdictions' com-

petition in corporate tax rates. Welfare is therefore always higher than in the case of full decentralization. Interestingly, however, as under full autonomy and in contrast to conventional wisdom it is never optimal for the central planner to use immobile apportionment factors only. The formula weight placed on capital may even be higher than under full fiscal autonomy.

Underpinning our results are a number of simplifying assumptions. One such assumption is that labor is perfectly immobile and capital perfectly mobile. In reality, 
labor and especially certain segments of the labor force may be mobile, and labor mobility may even vary across countries. Furthermore, there exist obstacles that prevent capital from flowing freely across jurisdictions. Nevertheless, it seems to be plausible that capital is more mobile than labor, even in the U.S., where labor perhaps is more mobile across jurisdictions than in Europe, say. If labor is more mobile, a standard tax competition analysis cannot explain why U.S. states on average place the same formula weight on capital as on labor (see the discussion in the introduction). Our analysis may then be viewed as an explanation for this discrepancy of real world tax systems and the standard tax competition analysis.

Other simplifying assumption made are perfectly competitive local labor markets and full employment. In reality, labor market imperfections cause unemployment that is not reflected by our analysis. Intuitively, however, our results should carry over to a framework with unemployment. Under full autonomy in our framework, the reason for imposing a positive weight on capital is the resulting increase in wage income. In the presence of unemployment, this effect is replaced (if wage rates are fixed above the equilibrium level), or augmented by a positive employment effect, to the effect that an increase in the formula weight on capital reduces the tax burden on labor and unemployment. Hence, we should again obtain the result that each jurisdiction places some positive weight on capital. Similarly, the wage income externality is replaced or augmented by an unemployment externality so that a tax rate change in one country alters unemployment in other countries. It is therefore plausible that the results in our centralized setting carry over to a world with unemployment, too.

Our analysis has also omitted important facts about countries. One such is that countries differ, and that some countries are so large that the world interest rate may be affected by public policy. An analysis of asymmetric countries, where one country is so large that its policy affects the world interest rate, is a topic left for future research. Even so, we believe that our basic arguments would survive under such extensions. 


\section{Appendix}

\section{A.1 Comparative Statics of Profit Maximization}

We start by deriving the changes in the effective tax rate $\bar{\tau}$ and its derivatives in (9). Employing the symmetry assumption in (9) immediately implies

$$
\frac{\partial \bar{\tau}}{\partial k_{i}}=\frac{\partial \bar{\tau}}{\partial \ell_{i}}=0
$$

for $i \in\{a, b\}$. Differentiating (6) and then using the symmetry property yields

$$
\frac{\partial \bar{\tau}}{\partial \tau_{i}}=\frac{1}{2}, \quad \frac{\partial \bar{\tau}}{\partial \gamma_{i}}=0
$$

for $i \in\{a, b\}$. From (9) and the symmetry assumption we obtain

$$
\frac{\partial^{2} \bar{\tau}}{\partial k_{i} \partial k_{j}}=\frac{\partial^{2} \bar{\tau}}{\partial \ell_{i} \partial \ell_{j}}=\frac{\partial^{2} \bar{\tau}}{\partial k_{i} \partial \ell_{j}}=0
$$

for $i, j \in\{a, b\}$ and

$$
\begin{array}{cl}
\frac{\partial^{2} \bar{\tau}}{\partial k_{i} \partial \tau_{i}}=-\frac{\partial^{2} \bar{\tau}}{\partial k_{i} \partial \tau_{j}}=\frac{\gamma}{4 k}, & \frac{\partial^{2} \bar{\tau}}{\partial k_{i} \partial \gamma_{i}}=-\frac{\partial^{2} \bar{\tau}}{\partial k_{i} \partial \gamma_{j}}=\frac{\tau}{4 k}, \\
\frac{\partial^{2} \bar{\tau}}{\partial \ell_{i} \partial \tau_{i}}=-\frac{\partial^{2} \bar{\tau}}{\partial \ell_{i} \partial \tau_{j}}=\frac{1-\gamma}{4 \ell}, & \frac{\partial^{2} \bar{\tau}}{\partial \ell_{i} \partial \gamma_{i}}=-\frac{\partial^{2} \bar{\tau}}{\partial \ell_{i} \partial \gamma_{j}}=-\frac{\tau}{4 \ell}
\end{array}
$$

for $i, j \in\{a, b\}$ and $i \neq j$. With the help of (33)-(37), totally differentiating (7) and (8) yields the matrix equation

$$
\begin{aligned}
& {\left[\begin{array}{cccc}
(1-\tau) F_{k k} & 0 & 0 & 0 \\
0 & (1-\tau) F_{k k} & 0 & 0 \\
(1-\tau) F_{k \ell} & 0 & -(1-\tau) & 0 \\
0 & (1-\tau) F_{k \ell} & 0 & -(1-\tau)
\end{array}\right]\left[\begin{array}{c}
\mathrm{d} k_{a} \\
\mathrm{~d} k_{b} \\
\mathrm{~d} w_{a} \\
\mathrm{~d} w_{b}
\end{array}\right] } \\
&= {\left[\begin{array}{cccc}
\sigma+\frac{\gamma \pi_{t}}{2 k} & \sigma-\frac{\gamma \pi_{t}}{2 k} & \frac{\tau \pi_{t}}{2 k} & -\frac{\tau \pi_{t}}{2 k} \\
\sigma-\frac{\gamma \pi_{t}}{2 k} & \sigma+\frac{\gamma \pi_{t}}{2 k} & -\frac{\tau \pi_{t}}{2 k} & \frac{\tau \pi_{t}}{2 k} \\
\frac{(1-\gamma) \pi_{t}}{2 \bar{\ell}} & -\frac{(1-\gamma) \pi_{t}}{2 \bar{\ell}} & -\frac{\tau \pi_{t}}{2 \bar{\ell}} & \frac{\tau \pi_{t}}{2 \bar{\ell}} \\
-\frac{(1-\gamma) \pi_{t}}{2 \bar{\ell}} & \frac{(1-\gamma) \pi_{t}}{2 \bar{\ell}} & \frac{\tau \pi_{t}}{2 \bar{\ell}} & -\frac{\tau \pi_{t}}{2 \bar{\ell}}
\end{array}\right]\left[\begin{array}{c}
\mathrm{d} \tau_{a} \\
\mathrm{~d} \tau_{b} \\
\mathrm{~d} \gamma_{a} \\
\mathrm{~d} \gamma_{b}
\end{array}\right] }
\end{aligned}
$$

with $\sigma$ defined in (12). Applying Cramer's rule and rearranging gives (10)-(15). 
In order to prove (16) note that since $F\left(k_{i}, \ell_{i}\right)$ is homogenous of degree $\eta$, there exists a function $H\left(k_{i} / \ell_{i}\right)=F\left(k_{i} / \ell_{i}, 1\right)$ with $H^{\prime}\left(k_{i} / \ell_{i}\right)=F_{k}\left(k_{i} / \ell_{i}, 1\right)>0$ and $H^{\prime \prime}\left(k_{i} / \ell_{i}\right)=$ $F_{k k}\left(k_{i} / \ell_{i}, 1\right)<0$ so that the production function and its derivatives can be written as

$$
\begin{gathered}
F\left(k_{i}, \ell_{i}\right)=\ell_{i}^{\eta} H\left(k_{i} / \ell_{i}\right), \quad F_{k}\left(k_{i}, \ell_{i}\right)=\ell_{i}^{\eta-1} H^{\prime}\left(k_{i} / \ell_{i}\right) \\
F_{k k}\left(k_{i}, \ell_{i}\right)=\ell_{i}^{\eta-2} H^{\prime \prime}\left(k_{i} / \ell_{i}\right), \quad F_{k \ell}\left(k_{i}, \ell_{i}\right)=(\eta-1) \ell_{i}^{\eta-2} H^{\prime}\left(k_{i} / \ell_{i}\right)-\ell_{i}^{\eta-3} k_{i} H^{\prime \prime}\left(k_{i} / \ell_{i}\right)
\end{gathered}
$$

Applying Cramer's rule to the matrix equation (38) and using the information from equation (40) yields the expression in equation (16).

\section{A.2 Proof of Proposition 1}

Differentiating equation (22) with respect to country $i$ 's formula weight, using equations (1), (7), (9), and (12) and in a last step applying the symmetry property yields

$$
\frac{\partial W(\cdot)}{\partial \gamma_{i}}=U_{c}\left[\bar{\ell}\left(\frac{\partial w_{i}}{\partial \gamma_{i}}+\frac{\partial w_{j}}{\partial \gamma_{i}}\right)+\frac{d \pi}{d \gamma_{i}}\right]+U_{g}\left[2 \tau^{*} \sigma\left(\frac{\partial k_{i}}{\partial \gamma_{i}}+\frac{\partial k_{j}}{\partial \gamma_{i}}\right)-\tau^{*} \bar{\ell}\left(\frac{\partial w_{i}}{\partial \gamma_{i}}+\frac{\partial w_{j}}{\partial \gamma_{i}}\right)\right]
$$

The expression $d \pi / d \gamma_{i}$ represents the total derivative of the multinational's maximized after-tax profit with respect to the formula weight. Calculating this total derivative, we obtain $d \pi / d \gamma_{i}=0$ due to equation (18) and the symmetry assumption. Equation (18) also implies that all parentheses in the above equation vanish so that we obtain $\partial W(\cdot) / \partial \gamma_{i}=0$ for all $\gamma_{i} \in[0,1]$ for $i \in\{a, b\}$. This proves that the central planner is indifferent between all formula weights.

In order to show that when a central planner maximizes joint welfare, he chooses the tax rates such that $U_{g} / U_{c}=1$ if $\rho=1$, and $U_{g} / U_{c}>1$ if $\rho \in[0,1[$, we differentiate (22) with respect to country $i$ 's tax rate using the same steps as above. This yields the first-order condition

$$
\begin{aligned}
\frac{\partial W(\cdot)}{\partial \tau_{i}}=U_{c}[ & \left.\bar{\ell}\left(\frac{\partial w_{i}}{\partial \tau_{i}}+\frac{\partial w_{j}}{\partial \tau_{i}}\right)+\frac{d \pi}{d \tau_{i}}\right] \\
& +U_{g}\left[\pi_{t}+2 \tau^{*} \sigma\left(\frac{\partial k_{i}}{\partial \tau_{i}}+\frac{\partial k_{j}}{\partial \tau_{i}}\right)-\tau^{*} \bar{\ell}\left(\frac{\partial w_{i}}{\partial \tau_{i}}+\frac{\partial w_{j}}{\partial \tau_{i}}\right)\right]=0 .
\end{aligned}
$$

The total derivative of the after-tax profit with respect to the tax rate is given by

$$
\frac{d \pi}{d \tau_{i}}=-\pi_{t}-\left(1-\tau^{*}\right) \bar{\ell}\left(\frac{\partial w_{i}}{\partial \tau_{i}}+\frac{\partial w_{j}}{\partial \tau_{i}}\right)
$$


Consider first the case $\rho=1$. Then $\sigma=0$ and equation (17) implies that all parentheses in equations (42) and (43) vanish. We obtain $\partial W(\cdot) / \partial \tau_{i}=\pi_{t}\left(U_{g}-U_{c}\right)=0$ and, thus, $U_{g} / U_{c}=1$ as claimed. For $\rho \in[0,1$ [ the parentheses in equations (42) and (43) are different from zero. Inserting equation (17) and rearranging equation (42) then yields

$$
\frac{U_{g}}{U_{c}}=1-\frac{U_{g}}{U_{c}} \frac{4 \tau^{*} \sigma^{2}}{\left(1-\tau^{*}\right) \pi_{t} F_{k k}-2 \tau^{*} \bar{\ell} \sigma F_{k \ell}}>1 .
$$

The inequality follows from $\sigma>0, F_{k k}<0$ and $F_{k \ell}>0$.

\section{A.3 Proof of Proposition 3}

Recall from Proposition 2 that the jurisdictions choose an interior solution $\gamma^{d}>0$ with respect to the formula weight. Hence, equation (24) implies the first-order condition $\partial V^{i}(\cdot) / \partial \gamma_{i}=0$. Using the comparative static results (15) and (16) of the multinational's behavior in this first-order condition gives

$$
U_{c} \frac{\bar{\ell} \pi_{t}}{2\left(1-\tau^{d}\right) F_{k k}}\left(\frac{F_{k k}}{\bar{\ell}}+\frac{F_{k \ell}}{k}\right)+U_{g} \frac{\tau^{d} \gamma^{d} \pi_{t}^{2}}{2 k^{2}\left(1-\tau^{d}\right) F_{k k}}=0 .
$$

Summing the externalities in equations (27)-(30) yields

$$
\begin{aligned}
\frac{\partial V^{j}(\cdot)}{\partial \tau_{i}}=U_{c} \frac{\tau^{d} \pi_{t}}{2\left(1-\tau^{d}\right)} & +\left(U_{c}-U_{g}\right) \frac{\tau^{d} \sigma \bar{\ell} F_{k \ell}}{\left(1-\tau^{d}\right) F_{k k}}+U_{g} \frac{2 \tau^{d} \sigma^{2}}{\left(1-\tau^{d}\right) F_{k k}} \\
& -U_{c} \frac{\bar{\ell} \gamma^{d} \pi_{t}}{2\left(1-\tau^{d}\right) F_{k k}}\left(\frac{F_{k k}}{\bar{\ell}}+\frac{F_{k \ell}}{k}\right)-U_{g} \frac{\tau^{d} \gamma^{d 2} \pi_{t}^{2}}{2 k^{2}\left(1-\tau^{d}\right) F_{k k}} .
\end{aligned}
$$

The two terms in the second row of equation (45) are zero due to equation (44). If $\rho=1$, we have $\sigma=0$ so that only the first term on the RHS of (45) remains. This term is positive so that $\tau^{d}<\tau^{*}$ (as claimed). In contrast, for $\rho \in[0,1[$ and $\sigma>0$ the second and third terms do not vanish, and the cross effect of the tax rate may take any sign. This can be shown by an example. Suppose capital cost is not deductible at all $(\rho=0)$ and the production function is Cobb-Douglas, i.e. $F\left(k_{i}, \ell_{i}\right)=k_{i}^{\alpha} \ell_{i}^{\beta}$ with $\alpha, \beta>0$ and $\alpha+\beta<1$. It is then straightforward to show

$$
\frac{\partial V^{j}(\cdot)}{\partial \tau_{i}} \gtreqless 0 \quad \Leftrightarrow \quad \frac{U_{g}}{U_{c}} \lesseqgtr \frac{1-\alpha-\beta}{\alpha(1-\beta)} .
$$

It is clear from this relation that we can always construct examples with inefficient undertaxation $\left(\tau^{d}<\tau^{*}\right)$ or inefficient overtaxation $\left(\tau^{d}>\tau^{*}\right)$. 


\section{A.4 Proof of Proposition 4}

The function $\Phi(\tau, \gamma)$ is identical to equation (45) if we replace $\tau^{d}$ by $\tau$ and $\gamma^{d}$ by $\gamma$. This expression is quadratic and, thus, U-shaped in $\gamma$. The first derivative reads

$$
\frac{\partial \Phi(\cdot)}{\partial \gamma}=-U_{c} \frac{\bar{\ell} \pi_{t}}{2(1-\tau) F_{k k}}\left(\frac{F_{k k}}{\bar{\ell}}+\frac{F_{k \ell}}{k}\right)-U_{g} \frac{\tau \pi_{t}^{2}}{k^{2}(1-\tau) F_{k k}} \gamma
$$

Consider first the case $\rho=1$. We then have $\sigma=0$ and

$$
\Phi(\tau, 0)=U_{c} \frac{\tau \pi_{t}}{2(1-\tau)}>0,\left.\quad \frac{\partial \Phi(\cdot)}{\partial \gamma}\right|_{\gamma=0}=-U_{c} \frac{\bar{\ell} \pi_{t}}{2(1-\tau) F_{k k}}\left(\frac{F_{k k}}{\bar{\ell}}+\frac{F_{k \ell}}{k}\right)<0 .
$$

The sign of the second expression follows from $F_{k k} / \bar{\ell}+F_{k \ell} / k<0$ already used in equation (16). Starting at $\gamma=0$, equation (47) shows that the central planner can reduce $|\Phi(\tau, \gamma)|$ by increasing $\gamma$ to a positive value. It then follows that $\gamma^{c}>0$. Similarly, for $\gamma=\gamma^{d}$, we know that the countries choose $\tau=\tau^{d}$, and that the pair $\left(\gamma^{d}, \tau^{d}\right)$ satisfies equation (44). From equations (45) and (46) it then follows that

$$
\Phi\left(\tau^{d}, \gamma^{d}\right)=U_{c} \frac{\tau^{d} \pi_{t}}{2\left(1-\tau^{d}\right)}>0,\left.\quad \frac{\partial \Phi(\cdot)}{\partial \gamma}\right|_{\gamma=\gamma^{d}}=-U_{g} \frac{\tau^{d} \pi_{t}^{2}}{2 k^{2}\left(1-\tau^{d}\right) F_{k k}} \gamma^{d}>0 .
$$

This implies $\gamma^{c}<\gamma^{d}$ and completes the proof for the case of $\rho=1$. If $\rho \in[0,1[$ and $\sigma>$ 0 , the sign of the derivatives of $\Phi$ at $\gamma=0$ and $\gamma=\gamma^{d}$, are the same as in equations (47) and (48), respectively. However, equation (45) shows that both $\Phi(\tau, 0)$ and $\Phi\left(\tau^{d}, \gamma^{d}\right)$ may now be positive or negative. In addition, we need the property that $\gamma=0$ implies $\tau=\tau^{d}$, since equations (31), (44) and (45) imply $\Phi\left(\tau^{d}, 0\right)=\Phi\left(\tau^{d}, \gamma^{d}\right)=\Psi\left(\tau^{d}\right)$, i.e. $\tau=\tau^{d}$ has to be the solution to equation (32) if $\gamma=0$. Since $\Phi\left(\tau^{d}, 0\right)$ and $\Phi\left(\tau^{d}, \gamma^{d}\right)$ are equal, they are either both positive or both negative. If they are positive, we have the same result as in case of $\rho=1$, i.e. $\left.\gamma^{c} \in\right] 0, \gamma^{d}[$. But if they are negative, it is always better for the social planner to choose $\gamma^{c}>\gamma^{d}$ since, according to $\left.\left[\partial \Phi(\cdot) / \partial \gamma_{i}\right]\right|_{\gamma=\gamma^{d}}>0$ and the U-shape of $\Phi$, the function $\Phi\left(\tau^{d}, \gamma\right)$ then comes closer to zero than for any other formula weight $\gamma \in\left[0, \gamma^{d}\right]$.

\section{References}

Anand, B. and R. Sansing (2000), 'The Weighting Game: Formula Apportionment as an Instrument of Public Policy', National Tax Journal 53, 183-199. 
Commission of the European Communities (2001a), Company Taxation in the Internal Market, [SEC(2001) 1681], Brussels.

Commission of the European Communities (2001b), Towards an Internal Market without Tax Obstacles, [COM (2001) 582 Final], Brussels.

Eggert, W. and G. Schjelderup (2003), 'Symmetric Tax Competition under Formula Apportionment', Journal of Public Economic Theory 5, 439-46.

Gérard, M. (2005), 'Multijurisdictional Firms and Governments' Strategies under Alternative Tax Designs', CESifo Working Paper No. 1527, University of Munich.

Gérard, M. (2006), 'Reforming the Taxation of Multijurisdictional Enterprises in Europe, A Tentative Appraisal', CESifo Working Paper No. 1795, University of Munich.

Gordon, R. (1986), 'Taxation of Investment and Savings in the World Economy', American Economic Review 76, 1086-1102.

Gordon, R. and J.D. Wilson (1986), 'An Examination of Multijurisdictional Corporate Income Taxation under Formula Apportionment', Econometrica 54, 1357-73.

Keen, M. and H. Piekkola (1997), 'Simple Rules for the Optimal Taxation of International Capital Income', Scandinavian Journal of Economics 99, 447-61.

Kind, H.J., Midelfart, K.H. and G. Schjelderup (2005), 'Corporate Tax Systems, Multinational Enterprises, and Economic Integration, Journal of International Economics 65, 507-21.

Martens-Weiner, J.M. (2005a), 'Formulary Apportionment and Group Taxation in the European Union: Insights from the United States and Canada', European Commission Taxation Papers, No. 8, Brussels.

Martens-Weiner, J. (2005b), Company Tax Reform in the European Union: Guidance from the United States and Canada on Implementing Formulary Apportionment in the EU, Springer.

McLure, C.E. (1980), 'The State Corporate Income Tax: Lambs in Wolves' Clothing', in: Aaron, A.J. and M.J. Boskin (Eds.), The Economics of Taxation, Washington DC: The Brookings Institution, 327-36. 
Nielsen, S.B., Raimondos-Møller, P. and G. Schjelderup (2003), 'Formula Apportionment and Transfer Pricing under Oligopolistic Competition', Journal of Public Economic Theory 5, 419-37.

Nielsen, S.B., Raimondos-Møller, P. and G. Schjelderup (2004), 'Company Taxation and Tax Spillovers: Separate Accounting versus Formula Apportionment', mimeo.

Pethig, R. and A. Wagener (2006), 'Profit Tax Competition and Formula Apportionment', International Tax and Public Finance, forthcoming.

Riedel, N. and M. Runkel (2006), 'Company Tax Reform with a Water's Edge', Journal of Public Economics, forthcoming.

Sørensen, P.B. (2004), 'Company Tax Reform in the European Union', International Tax and Public Finance 11, 91-115.

Wellisch, D. (2004), 'Taxation under Formula Apportionment - Tax Competition, Tax Incidence, and the Choice of Apportionment Factors', Finanzarchiv 60, 24-41. 


\section{CESifo Working Paper Series}

for full list see www.cesifo-group.org/wp

(address: Poschingerstr. 5, 81679 Munich, Germany, office@cesifo.de)

2008 Mikael Priks, Judiciaries in Corrupt Societies, June 2007

2009 Steinar Holden and Fredrik Wulfsberg, Downward Nominal Wage Rigidity in the OECD, June 2007

2010 Emmanuel Dhyne, Catherine Fuss, Hashem Pesaran and Patrick Sevestre, Lumpy Price Adjustments: A Microeconometric Analysis, June 2007

2011 Paul Belleflamme and Eric Toulemonde, Negative Intra-Group Externalities in TwoSided Markets, June 2007

2012 Carlos Alós-Ferrer, Georg Kirchsteiger and Markus Walzl, On the Evolution of Market Institutions: The Platform Design Paradox, June 2007

2013 Axel Dreher and Martin Gassebner, Greasing the Wheels of Entrepreneurship? The Impact of Regulations and Corruption on Firm Entry, June 2007

2014 Dominique Demougin and Claude Fluet, Rules of Proof, Courts, and Incentives, June 2007

2015 Stefan Lachenmaier and Horst Rottmann, Effects of Innovation on Employment: A Dynamic Panel Analysis, June 2007

2016 Torsten Persson and Guido Tabellini, The Growth Effect of Democracy: Is it Heterogenous and how can it be Estimated?, June 2007

2017 Lorenz Blume, Jens Müller, Stefan Voigt and Carsten Wolf, The Economic Effects of Constitutions: Replicating - and Extending - Persson and Tabellini, June 2007

2018 Hartmut Egger and Gabriel Felbermayr, Endogenous Skill Formation and the Source Country Effects of International Labor Market Integration, June 2007

2019 Bruno Frey, Overprotected Politicians, June 2007

2020 Jan Thomas Martini, Rainer Niemann and Dirk Simons, Transfer Pricing or Formula Apportionment? Tax-Induced Distortions of Multinationals' Investment and Production Decisions, June 2007

2021 Andreas Bühn, Alexander Karmann and Friedrich Schneider, Size and Development of the Shadow Economy and of Do-it-yourself Activities in Germany, June 2007

2022 Michael Rauscher and Edward B. Barbier, Biodiversity and Geography, June 2007

2023 Gunther Schnabl, Exchange Rate Volatility and Growth in Emerging Europe and East Asia, June 2007 
2024 Erkki Koskela and Ronnie Schöb, Tax Progression under Collective Wage Bargaining and Individual Effort Determination, June 2007

2025 Jay Pil Choi and Marcel Thum, The Economics of Politically Connected Firms, June 2007

2026 Jukka Pirttilä and Roope Uusitalo, Leaky Bucket in the Real World: Estimating Inequality Aversion Using Survey Data, June 2007

2027 Ruslan Lukach, Peter M. Kort and Joseph Plasmans, Strategic R\&D with Knowledge Spillovers and Endogenous Time to Complete, June 2007

2028 Jarko Fidrmuc, Neil Foster and Johann Scharler, Labour Market Rigidities, Financial Integration and International Risk Sharing in the OECD, June 2007

2029 Bernardina Algieri and Thierry Bracke, Patterns of Current Account Adjustment Insights from Past Experience, June 2007

2030 Robert Dur and Hein Roelfsema, Social Exchange and Common Agency in Organizations, June 2007

2031 Alexander Libman and Lars P. Feld, Strategic Tax Collection and Fiscal Decentralisation: The Case of Russia, June 2007

2032 Øystein Foros, Hans Jarle Kind and Greg Shaffer, Resale Price Maintenance and Restrictions on Dominant Firm and Industry-Wide Adoption, June 2007

2033 Jan K. Brueckner and Kurt Van Dender, Atomistic Congestion Tolls at Concentrated Airports? Seeking a Unified View in the Internalization Debate, June 2007

2034 Viet Do and Ngo Van Long, International Outsourcing under Monopolistic Competition: Winners and Losers, June 2007

2035 Nadia Fiorino and Roberto Ricciuti, Determinants of Direct Democracy, June 2007

2036 Burkhard Heer and Alfred Maussner, Inflation and Output Dynamics in a Model with Labor Market Search and Capital Accumulation, June 2007

2037 Konstantinos Angelopoulos, Jim Malley and Apostolis Philippopoulos, Public Education Expenditure, Growth and Welfare, June 2007

2038 Maarten Bosker, Steven Brakman, Harry Garretsen and Marc Schramm, Adding Geography to the New Economic Geography, June 2007

2039 Steffen Henzel, Oliver Hülsewig, Eric Mayer and Timo Wollmershäuser, The Price Puzzle Revisited: Can the Cost Channel Explain a Rise in Inflation after a Monetary Policy Shock?, July 2007

2040 Rosario Crinò, Service Offshoring and White-Collar Employment, July 2007 
2041 Carsten Hefeker and Michael Neugart, Labor Market Regulation and the Legal System, July 2007

2042 Bart Cockx and Muriel Dejemeppe, Is the Notification of Monitoring a Threat to the Unemployed? A Regression Discontinuity Approach, July 2007

2043 Alfons J. Weichenrieder, Profit Shifting in the EU: Evidence from Germany, July 2007

2044 Annika Alexius and Bertil Holmlund, Monetary Policy and Swedish Unemployment Fluctuations, July 2007

2045 Axel Dreher, Jan-Egbert Sturm and Jakob de Haan, Does High Inflation Cause Central Bankers to Lose their Job? Evidence Based on a New Data Set, July 2007

2046 Guglielmo Maria Caporale and Luis A. Gil-Alana, Long Run and Cyclical Dynamics in the US Stock Market, July 2007

2047 Alessandro Balestrino, It is a Theft but not a Crime, July 2007

2048 Daniel Becker and Michael Rauscher, Fiscal Competition in Space and Time: An Endogenous-Growth Approach, July 2007

2049 Yannis M. Ioannides, Henry G. Overman, Esteban Rossi-Hansberg and Kurt Schmidheiny, The Effect of Information and Communication Technologies on Urban Structure, July 2007

2050 Hans-Werner Sinn, Please bring me the New York Times - On the European Roots of Richard Abel Musgrave, July 2007

2051 Gunther Schnabl and Christian Danne, A Role Model for China? Exchange Rate Flexibility and Monetary Policy in Japan, July 2007

2052 Joseph Plasmans, Jorge Fornero and Tomasz Michalak, A Microfounded Sectoral Model for Open Economies, July 2007

2053 Vesa Kanniainen and Panu Poutvaara, Imperfect Transmission of Tacit Knowledge and other Barriers to Entrepreneurship, July 2007

2054 Marko Koethenbuerger, Federal Tax-Transfer Policy and Intergovernmental PreCommitment, July 2007

2055 Hendrik Jürges and Kerstin Schneider, What Can Go Wrong Will Go Wrong: Birthday Effects and Early Tracking in the German School System, July 2007

2056 Bahram Pesaran and M. Hashem Pesaran, Modelling Volatilities and Conditional Correlations in Futures Markets with a Multivariate t Distribution, July 2007

2057 Walter H. Fisher and Christian Keuschnigg, Pension Reform and Labor Market Incentives, July 2007 
2058 Martin Altemeyer-Bartscher, Dirk T. G. Rübbelke and Eytan Sheshinski, Policies to Internalize Reciprocal International Spillovers, July 2007

2059 Kurt R. Brekke, Astrid L. Grasdal and Tor Helge Holmås, Regulation and Pricing of Pharmaceuticals: Reference Pricing or Price Cap Regulation?, July 2007

2060 Tigran Poghosyan and Jakob de Haan, Interest Rate Linkages in EMU Countries: A Rolling Threshold Vector Error-Correction Approach, July 2007

2061 Robert Dur and Klaas Staal, Local Public Good Provision, Municipal Consolidation, and National Transfers, July 2007

2062 Helge Berger and Anika Holler, What Determines Fiscal Policy? Evidence from German States, July 2007

2063 Ernesto Reuben and Arno Riedl, Public Goods Provision and Sanctioning in Privileged Groups, July 2007

2064 Jan Hanousek, Dana Hajkova and Randall K. Filer, A Rise by Any Other Name? Sensitivity of Growth Regressions to Data Source, July 2007

2065 Yin-Wong Cheung and Xing Wang Qian, Hoarding of International Reserves: Mrs Machlup's Wardrobe and the Joneses, July 2007

2066 Sheilagh Ogilvie, 'Whatever Is, Is Right'?, Economic Institutions in Pre-Industrial Europe (Tawney Lecture 2006), August 2007

2067 Floriana Cerniglia and Laura Pagani, The European Union and the Member States: Which Level of Government Should Do what? An Empirical Analysis of Europeans' Preferences, August 2007

2068 Alessandro Balestrino and Cinzia Ciardi, Social Norms, Cognitive Dissonance and the Timing of Marriage, August 2007

2069 Massimo Bordignon, Exit and Voice. Yardstick versus Fiscal Competition across Governments, August 2007

2070 Emily Blanchard and Gerald Willmann, Political Stasis or Protectionist Rut? Policy Mechanisms for Trade Reform in a Democracy, August 2007

2071 Maarten Bosker and Harry Garretsen, Trade Costs, Market Access and Economic Geography: Why the Empirical Specification of Trade Costs Matters, August 2007

2072 Marco Runkel and Guttorm Schjelderup, The Choice of Apportionment Factors under Formula Apportionment, August 2007 